\title{
Clashing nations back SESAME
}

\section{Participants put politics aside to find cash for construction of Middle-East synchrotron.}

\section{BY GEOFF BRUMFIEL}

I

srael and Iran can agree on little these days, but they have found common ground in a scientific project.

Despite brinkmanship over Iran's nuclear programme, the two nations have joined with Jordan and Turkey to commit crucial funding to the construction of Synchrotron-light for Experimental Science and Applications in the Middle East (SESAME). Under an agreement announced on 13 March, the partners have promised a total of US\$20 million towards the construction of the project. SESAME is now looking for a further $\$ 15$ million from other partner nations to complete the synchrotron's first four beamlines in 2015 .

"The fact that we could get such an agreement given the political situation is kind of remarkable," says Chris Llewellyn Smith, the president of SESAME's governing council and a past director-general of CERN, Europe's particle-physics lab near Geneva, Switzerland.
Based in Allan, outside Amman, Jordan, SESAME aims to build scientific expertise in its member countries and bolster cultural ties between them. When completed, the \$110-million machine would be the Middle East's only source of high-intensity synchrotron X-rays, which are used in fundamental research ranging from molecular biology to materials science.

The project mirrors the organization of CERN, but Amman is a long way from Geneva - metaphorically as well as literally. In recent years, SESAME has had to contend with the assassination of two members of its Iranian delegation and huge political upheavals in partner countries including Egypt.

Despite the tensions, scientists involved with the project say that SESAME is succeeding because it has something to offer all the participants. Israel, for example, gets a worldclass research facility on its doorstep and an opportunity to show its willingness to collaborate with neighbours, says Eliezer Rabinovici, director of the Institute for Advanced Studies at the Hebrew University of Jerusalem, and a member of SESAME's council. Other member states see an opportunity to educate a young and rapidly growing science base. "Turkey is also interested in developing similar laboratories and SESAME would be a very good experience," says Zehra Sayers, a physicist at Sabanc1 University in Istanbul and head of SESAME's scientific advisory committee.

Llewellyn Smith is optimistic that the remaining money can be found. Now that local partners have committed funding, the project is more likely to gain support from outsiders such as the United States and the European Union. And other partners in the Middle East, notably Egypt, may yet provide cash, although political turmoil could make commitments difficult.

Rabinovici says that SESAME shows the strength of scientific collaboration, even under the most difficult circumstances. "This is an existence proof that scientists can, at least for a period of time, transcend the politics around them," he says. 